\title{
Exploring MIP Sensor of Basal Stem Rot (BSR) Disease in Palm Oil Plantation
}

\author{
A.H. Abdullah', A.Y.Md. Shakaff', A.H. Adom ${ }^{1}$, M.N. Ahmad', A. Zakaria', S.A. Ghani, N.M. \\ Samsudin ${ }^{1}$, F.S.A. Saad ${ }^{1}$, L.M. Kamarudin ${ }^{1}$, N.H. Hamid ${ }^{2}$, I.A. Seman ${ }^{3}$ \\ ${ }^{1}$ Center of Excellence Advanced Sensor Technology, UniMAP, 01000 Kangar, Perlis, Malaysia \\ e-mail:abu.hassan@unimap.edu.my \\ ${ }^{2}$ Felda Agriculture Services SdnBhd (FASSB), Jalan Gurney Satu, 54000 Kuala Lumpur, Malaysia \\ ${ }^{3}$ Malaysian Palm Oil Board (MPOB), MPOB, Bandar BaruBangi, 43000 Kajang, Selangor, Malaysia
}

\begin{abstract}
:
In Malaysia, the production of palm oil is hampered by the infection of Basal Stem Rot (BSR) disease. Unfortunately, the existing BSR detection techniques are complex, time-consuming and still not fully developed. So, this research proposes an investigation to identify the volatile compounds (biomarkers) of the infected oil palm trees. The biomarkers will be proposed to develop specific Molecularly Imprinted Polymer (MIP) sensors. The sensor will be used for the development of 'Application Specific Electronic Nose' (ASEN). The samples were taken from healthy and infected BSR disease tree. Fourier Transform Infrared (FTIR) and Headspace Gas Chromatography Mass Spectrometry (GC-MS) analysis is used to identify the biomarkers. The results show that the technique has successfully detected and identified the volatile compounds biomarkers for BSR disease of infected oil palm tree.
\end{abstract}

Key words: BSR disease, FTIR, GC-MS, MIP and e-nose.

\section{Introduction}

Oil palm is a tropical perennial species which mainly used in foods, detergents and lubricants. Now the demand is soar because it is also being used for biofuel. Malaysia has 4.2 million hectares of palm oil that enables it to exceed natural rubber as the main cash crop [1]. The crop is susceptible to diseases, commonly fungus, pests and pathogens where Basal Stem Rot (BSR) is the main disease in Malaysia and Indonesia [2]. The Ganoderma boninense fungus is the sole causal agent of the disease in Malaysia [3]. The disease infection occurs when health roots contact with diseases tissues in the soil, wounded tissues or dead roots [4]. Then the fungus destroys the internal palm tissues, which eventually leads to the death of the tree [5]. It is estimated that if 2.5 per cent of the total acreage of oil palm plantation in Malaysia is affected by the disease, the industry would lose about RM80 million each year [6].

Currently, numbers of research works have been reported on the detection of Ganoderma boninense fungus and the BSR disease. The most common technique is the field symptom known as 'skirting' where some of the mature leave start to wilt, malnutrition and going down. The disease can also be detected from the rotten palm trunk base and the presence of small white button fruiting bodies (basidiomata) [7]. Other techniques include morphological characteristics, pathogenicity test, Polymerase Chain Reaction (PCR), Enzyme-Linked Immunosorbent Assay (ELISA), tomography and hyper-spectral reflectance data.

Unfortunately most of these techniques require complex procedure and still not fully developed. The techniques can only detect BSR by the presence of the fruiting bodies on the palm trunk base (see Fig. 1). At this stage the disease cannot be cured and the tree had already dead. Subsequently, the disease might spread to next adjacent trees. In addition, those techniques are also unable to provide real time results. The availability of speedy and accurate diagnostic techniques, for detecting Ganoderma boninense in oil palm at an early stage of infection, would benefit the industry.

The research is exploring the possibilities of identifying the BSR volatile compounds main chemical components (biomarkers) by using Fourier Transform Infrared (FTIR) and Headspace Gas Chromatography Mass Spectrometry (GC-MS). Specific chemical standard will be used to verify the biomarkers. The Ganoderma-selective medium (GSM) tissue culture will be used to validate the GCMS analysis result. The biomarkers also will be 
further quantified to the degree of the Ganoderma boninense infection. The biomarkers will be used to developed specific Molecularly Imprinted Polymer (MIP) sensors. The imprinting molecule is used as a template to form a receptor site with complementary binding features with regard to the molecules of the volatile compounds. The MIP substance contains of mixed chemical compounds that detect the biomarkers. The MIP is coated on Quartz Crystal Microbalance (QCM) where conducting polymer being used for binding. The sensor will be tested and characterise to verify the functionality.

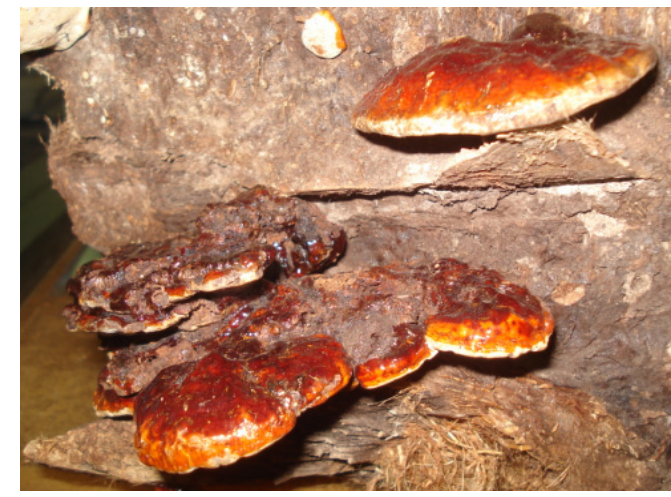

Fig.1: The Ganoderma boninense basidiomata.

The MIP sensors are used to develop an 'Application Specific Electronic Nose' (ASEN). The instrument consists of sensors, sensing chamber and microcontroller with embedded Artificial Neural Network (ANN) pattern recognition. The instrument will provide on-site early detection of the BSR disease in oil palm plantation.

\section{Methodology}

Sample of skin, soil, fruiting body and air around the stamp are taken from healthy and infected BSR disease tree. The samples are collected from the Federal Land Development Authority (FELDA) palm oil Research Station in Malaysia. The tree is being identified by BSR disease expert (FELDA staff with 20 years working experience in the oil palm plantation) by using field symptoms technique. The tree is being identified by Ganoderma expert (plant pathologist) and verify by using ELISA-PAb technique.

The Fourier Transform Infrared (FTIR) Spectroscopy is used to identify the Ganoderma boninense functional group. The FTIR spectrum has been obtained by using a Perkin Elmer 2000 Series Instrument (Perkin Elmor Cetus Instruments, Norwalk CT). The spectrum resolution is set at $4 \mathrm{~cm}^{-1}$ and the scanning range was selected from 600 to 4000 $\mathrm{cm}^{-1}$. The result of the analysis will be used to strategies the GC-MS analysis.

The GC-MS analysis is performed offline by using GC-MS Clarus 600T (Perkin Elmer, Massachusetts, USA) for the infected and healthy trunk sample. Five gram of each sample was added directly into $22 \mathrm{ml}$ headspace vial and seal with PTFE septa. The samples were kept in the glass jar for 6 hours to allow volatiles to concentrate before each measurement. The sample was scan of total ion current strength (TIC) from m/z 40-500 with incubation triplicate in Turbo Matrix Headspace Sampler for 60 minutes at $80^{\circ} \mathrm{C}$. Then it is analysed using Clarus $680 \mathrm{GC}$ for separation and Clarus 600T for mass analysis. The simplest data time is basically a chromatographic output representing a summation of the signal output from the mass spectrometer analyser which is a measurement of the TIC versus strength of all the ions produced by the mass spectrometer at a given time. The headspace compound identification is done by looking at the retention time and comparing with the known library standard and search hits.

\section{Results and discussion}

The FTIR spectrum result (see Fig. 2) and Table 1) shows summaries of the Ganoderma FTIR spectrum functional group analysis. The percentage transmittance of the absorption analysis has been identified and the Ganoderma functional groups were carbohydrate, hemicellulose and lignocellulose.

Table 1: Functional Group of Ganoderma

\begin{tabular}{|c|c|c|}
\hline $\begin{array}{c}\text { W.length } \\
\left(\mathrm{cm}^{-1}\right)\end{array}$ & $\begin{array}{c}\text { Functional } \\
\text { Group }\end{array}$ & $\begin{array}{c}\text { Organic } \\
\text { Compound }\end{array}$ \\
\hline 3846.96 & $\begin{array}{l}\text {-OH, } \\
\text { (Hydroxyl) }\end{array}$ & $\begin{array}{l}\text { 9(11),22-trien-3b- } \\
\text { ol, 2b,3a,9a- } \\
\text { trihydroxyergosta- } \\
\text { 7,22-diene }\end{array}$ \\
\hline 3003.63 & $\begin{array}{l}\mathrm{CH}_{3} \text { (Methyl) } \\
\text { or }-\mathrm{CH}_{2} \\
\text { (Methylene) }\end{array}$ & $\begin{array}{l}\text { All the compound } \\
\text { in table } 4\end{array}$ \\
\hline 2263.85 & CN (Cyanide) & Little toxic odour \\
\hline 1567.63 & Aromatic ring & $\begin{array}{l}\text { All the compound } \\
\text { in table } 4\end{array}$ \\
\hline 1190.63 & $\mathrm{C}-\mathrm{O}-\mathrm{C}$ & $\begin{array}{l}\text { ergosta-7,22- } \\
\text { dien-3b-yl } \\
\text { linoleate, ergosta- } \\
7,22 \text {-dien-3b-yl } \\
\text { palmitate }\end{array}$ \\
\hline 697.63 & $\begin{array}{l}\text { Si-O ( } \\
\text { Silicone) }\end{array}$ & $\begin{array}{l}\text { Small quantity for } \\
\text { odour binding }\end{array}$ \\
\hline
\end{tabular}




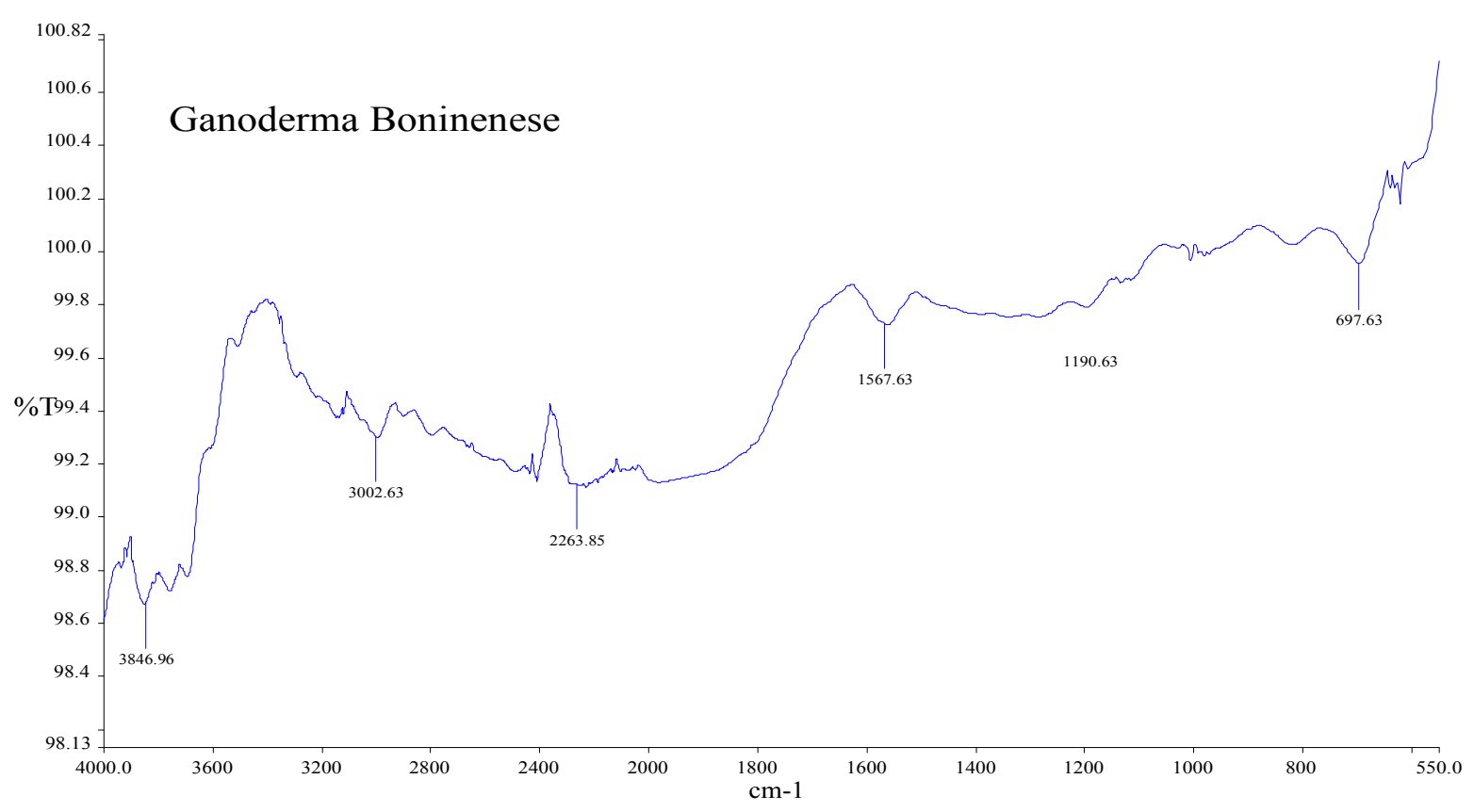

Fig. 2: FTIR for Ganoderma boninense

The GC-MS analysis result on the headspace volatile of the infected tree and non-infected tree trunk is able to identify the Ganoderma boninense biomarkers (see Fig. 3(a), (b) and $3(\mathrm{c})$ ). Two peaks of the result were identified as the volatile biomarkers of the infected BSR disease. MS search on these two peaks found that Benzene,1-Methyl-2-(2-Propenyl)- and Cyclohexasiloxane, dodecamethyl-. Calibration with standard chemicals will further ensure the integrity of these findings.

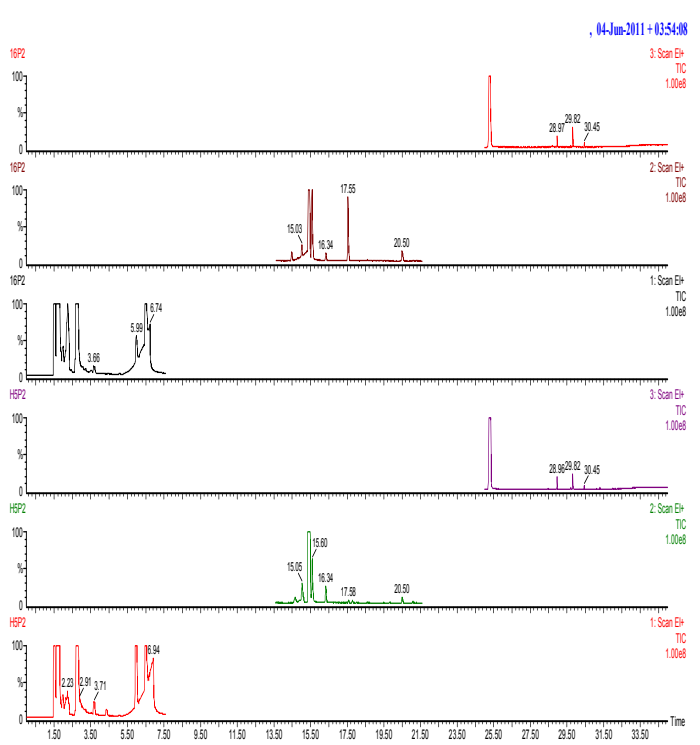

Figure 3(a): GC-MS for Ganoderma boninense

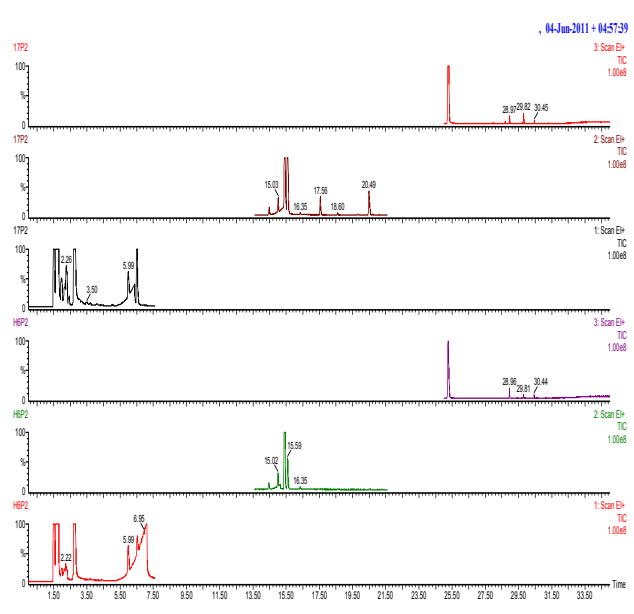

Figure 3(b): GC-MS for Ganodermaboninense

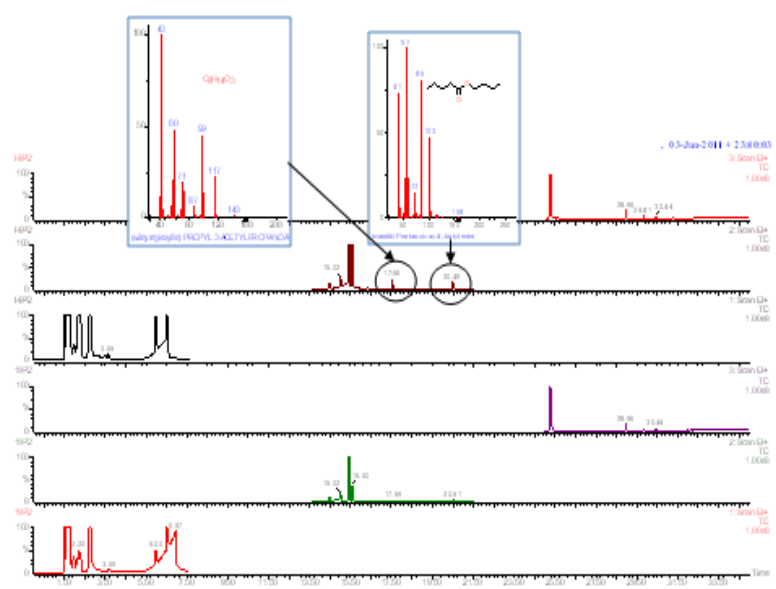

Figure 3(c): GC-MS for Ganoderma boninense 


\section{Conclusion}

This research is successfully identifying the volatile compounds component (biomarkers) for Ganoderma boninense fungus of the BSR infected oil palm trees. Fourier Transform Infrared (FTIR) and Headspace Gas Chromatography Mass Spectrometry (GCMS) are used to identify the biomarkers. Specific chemical standard will be used to verify the biomarkers. The finding will used to develop

\section{Acknowledgements}

This project is partly funded by the Malaysian Ministry of Higher Education under the Fundamental Research Grant Scheme (FRGS9003-00250). A.H. Abdullah gratefully acknowledges the leave granted by Universiti Malaysia Perlis (UniMAP) to allow him to pursue his Ph.D.

\section{References}

[1] A.C. Soh, C.K. Wong, Y.W. Ho, and C.W. Choong,Oil Palm J. Vollmann, I. Rajcan (eds.), Oil Crops, Handbook of Plant Breeding 4, (2010): doi: 10.1007/978-0-387-77594-4-11

[2] Azahar T. M., Mustapha, J.C., Mazliham, S. and Boursier,Temporal Analysis of Basal Stem Rot Disease in Oil Palm Plantations: An Analysis on Peat Soil, Int. Journal of Engineering \& Technology IJET-IJENS. Vol: 11 No: 03, (2011).

[3] A.C.Soh, C.K. Wong, Y.W.Ho, and C.W.Choong, "Oil Crops, Handbook of Plant Breeding 4", Oil Palm J. Vollmann, Springer Science Business Media, LLC, (2009).

[4] PD Turner, Oil Palm and Ganodermalll: Treatment and Control in Established Plantings, The Planter, 41:279-282, (1965).

[5] M. A. Markoma, A. Y. Md. Shakaff, A. H. Adom, M. N. Ahmad, W. Hidayat, A. H. Abdullah, and N. Ahmad Fikri, Computers and Electronicsin Agriculture 66, 140 (2009).

[6] H Singh, MN Ahmad, MZ Daud, F Khairul, AYM Shakaff and S Hamzah, Electronic Nose Application In Ganoderma Detection?, $1^{\text {st }}$. Research Seminar, KUKUM, Malaysia, (2006).

[7] CD Lelong, JM Roger, S Brégand, F Dubertret, Evaluation of Oil-Palm Fungal Disease Infestation with Canopy Hyperspectral Reflectance Data, Sensors, 10, 734-747,(2010). specific MIP sensors for 'Application Specific Electronic Nose' (ASEN) e-nose for detecting the degree of BSR infection. The results demonstrate that the technique has successfully detected and identified the volatile compound biomarkers for BSR disease of oil palm tree at high accuracy rate. This will enable preventive action to be taken to prolong the oil palm tree life cycle as well as preventing the disease from spreading to the whole plantation. 